This is an electronic reprint of the original article. This reprint may differ from the original in pagination and typographic detail.

Author(s): Lehkonen, Heikki; Heimonen, Kari

Title: $\quad$ Timescale-dependent stock market comovement: BRICs vs. developed markets

Year: $\quad 2014$

Version:

Please cite the original version:

Lehkonen, H., \& Heimonen, K. (2014). Timescale-dependent stock market comovement: BRICs vs. developed markets. Journal of Empirical Finance, 28(September), 90-103. https://doi.org/10.1016/j.jempfin.2014.06.002

All material supplied via JYX is protected by copyright and other intellectual property rights, and duplication or sale of all or part of any of the repository collections is not permitted, except that material may be duplicated by you for your research use or educational purposes in electronic or print form. You must obtain permission for any other use. Electronic or print copies may not be offered, whether for sale or otherwise to anyone who is not an authorised user. 


\title{
Timescale-Dependent Stock Market Comovement: BRICs vs. Developed Markets
}

\begin{abstract}
This paper examines the differences in the asset return comovement of the BRIC countries (Brazil, Russia, India and China), the other developed economies in their regions (Canada, Hong Kong and Australia) and the major industrialized economies (the U.K., Germany and Japan) with respect to the U.S. for different return periods. The novelty of the paper is that the stock return indices are decomposed to several timescales using wavelet analysis and that the results are further used as inputs for the dynamic conditional correlation (DCC) framework, which is used as a measure of comovement. The results propose that the level of stock market comovement depends on regional aspects, the level of development and especially on the timescale of returns. These factors should be carefully considered in designing internationally diversified portfolios. The BRICs provide some portfolio diversification benefits, but it is not justifiable to treat all BRICs as a homogeneous group of emerging economies in terms of stock market comovement.
\end{abstract}

JEL classification: C22, C40, E32, F30, G15

Keywords: International stock markets, BRIC, Comovement, Wavelets, Dynamic conditional correlation

\author{
Heikki Lehkonen* \\ School of Business and Economics \\ University of Jyväskylä \\ P.O. BOX 35 \\ FI-40014 University of Jyväskylä \\ FINLAND \\ heikki.lehkonen@jyu.fi \\ Kari Heimonen \\ School of Business and Economics \\ University of Jyväskylä \\ P.O. BOX 35 \\ FI-40014 University of Jyväskylä \\ FINLAND \\ kari.heimonen@jyu.fi
}

\footnotetext{
${ }^{*}$ Corresponding author. Tel. +358405767822 . Fax. +35814617194 . E-mail address: heikki.lehkonen@jyu.fi.
} 


\section{Introduction}

Stock market interdependence has been recognized as an important topic in international finance in both the developed and emerging markets (see, e.g., Korajczyj and Viallet (1989), Chan, Karolyi and Stulz (1992), Bekaert and Harvey (1995), Foerster and Karolyi (1999), Dumas, Harvey and Ruiz (2003), Carrieri, Errunza and Sarkissian (2004), Bekaert, Harvey and Ng (2005) and Carrieri, Errunza and Hogan (2007)). One of the major motivations for these studies is the exploration of the level of comovement in the international stock market, which impacts the portfolio diversification and the stability of the global financial system, given that shocks to the stock market can quickly spread across the world.

Growing importance of emerging market for global portfolio allocation calls for further research on the stock market integration and comovement among the emerging markets ${ }^{1}$. The purpose of this study is to reveal the time-dependencies and the evolving nature of stock market correlation among the BRIC countries (Brazil, Russia, India and China), the other important economies in their regions (Canada, Australia and Hong Kong) and the major industrialized countries (Germany, the U.K. and Japan) with respect to the U.S. As a result, we are able to make inferences about whether the BRIC countries' equity markets can be clustered into a single BRIC group and appropriate levels of stock market segmentation of BRIC countries compared to the U.S. and other major industrial economies. The analysis also provides some evidence of whether the stock markets could be divided into American, Asian and European regions. The time-dependence of the stock market comovement is carefully considered by combining wavelet analysis and dynamic condition correlation, which are relatively new techniques.

Emerging countries have received much interest during the last few decades, mainly because the economic performance of the BRIC countries has strongly exceeded the economic growth of industrialized countries. ${ }^{2}$ For many years, economic growth and stock market performance in the BRIC countries have exceeded the figures produced in more advanced economies and they have been recognized as motors for global economic growth. It is expected that under favorable economic growth conditions, the combined economies of the BRICs could grow larger than those of the combined economies of the G6 nations (the U.S., Japan, Germany, France, Italy and the United Kingdom) in the U.S. dollar terms in less than 40 years. Even today, emerging nations' equity markets have significant, sizeable and persistent impacts on the global equity markets (see Cuadro-Sáez et al. (2009)).

Since Longin and Solnik (1995) and Bekaert and Harvey (1995), it is recognized that stock market correlations and integrations are time-varying. In addition, Rua and Nunes (2009) provide evidence that the degree of stock return comovement varies also

\footnotetext{
1 Market interdependence and high market comovement often refer to high correlations between returns in different markets. Although, Bekaert and Harvey (1997) and Morana and Beltratti (2008) propose positive correlation between the correlation and the degree of market integration, correlation should not be used as a direct measure of integration as shown for example by Pukthuanthong and Roll (2009). In this research, we make no difference between the concepts of market comovement, correlation, interdependency and integration.

${ }^{2}$ The abbreviation BRIC has become an everyday term among finance professionals, and it is expected that the importance of these countries will grow in equity portfolios. The term BRIC was made famous by a Goldman Sachs's report by Wilson and Purushothaman (2003) and the follow-up paper by O'Neill et al. (2005).
} 
across different return frequencies. The dynamicity of the integration is even more evident for the emerging countries, which have just recently opened their markets and are now gradually integrating into the global stock market, as shown for example by de Jong and de Roon (2005). The time-dependence of comovement is important for stock markets, as the market participants are a very heterogeneous group. Active investors, such as large investment banks, are more interested in short-term movements of the indices than more passive investors, such as the commercial banks, insurance companies, individuals and financial arms of non-financial corporations that pay more attention to the long-term performance of the portfolio balances. Thus, investors from different groups are also associated with different risk characteristics.

Because the correlation of stock returns varies over time, the investigation must be able to capture this time-varying feature. It has been generally accepted that multivariate models are appropriate for studying transmission mechanisms and correlation dynamics between the markets (Martens and Poon, 2001). Along these lines, Bhar and Nikolova (2009) study the level of correlation of the BRIC countries with their respective regions and the world using a bivariate EGARCH structure, which allows for a time-varying conditional correlation of the index equity returns. They use return and volatility spillovers as proxies for the level of integration and find that India has the highest level of integration on regional and global levels, followed by Brazil and Russia, while China shows no evidence of regional integration. The weaknesses of their study are that they do not identify the differences between short- and long-term integration and fail to indicate the dynamics of the integration process.

The novel contribution of this study is to combine two rather new techniques, wavelet analysis and dynamic condition correlation (DCC), to reveal the stock market interdependencies between the BRIC countries and the more advanced economies at different return frequencies. The differences and the time-varying nature of stock market comovement are examined using the wavelet-DCC analysis. The multiresolution analysis of wavelets filters and disentangles the national stock market dynamics at different frequencies. The filtered series are further used as inputs for the DCC model by Engle (2002). As a result, we are able to detect the BRIC countries' stock market comovement at different frequencies and identify the timescales in which the comovement is higher and the benefits of portfolio diversification in terms of risk management are lower. ${ }^{3}$

We find that the dynamicity and strength of the correlation depend on the timescale of the returns such that for the lower timescales, the dynamicity is higher and the strength is lower than that for the higher timescales. The regional and developmental factors also play a role in stock market comovement. For the lower timescales, the clustering of Asian, European and American markets is justified, supporting the results of Groenen and Franses (2000), while for the higher timescales, the developmental factors begin to dominate as the developed markets become more interdependent than the BRICs. In general, we cannot find evidence of a positive time-trend in the correlations for the sample period.

\footnotetext{
${ }^{3}$ For previously applications of wavelets for stock market integration, see Rua and Nunes (2009) who used continuous wavelet transform framework. Our discrete version enables us to study more carefully the trend, dynamicity and strength of the correlation structure. For other applications of wavelets for economic research, see e.g Crowley and Lee (2005) who analyze the business cycles in the euro area and other industrialized economies.
} 
The rest of the paper is organized as follows. Section 2 presents the measure of comovement, briefly describes the wavelet decomposition and the dynamic conditional correlation. Section 3 provides the data and the results, while section 4 concludes.

\section{Measuring the comovement}

We study the emerging market time-varying stock market comovement in terms of the U.S. investor. Our contribution to the theories of market integration (see. e.g. Black (1974); Stulz (1981); Errunza and Losq (1985); Eun and Janakiramanan (1986); Bekaert and Harvey (1995); Cooper and Kaplanis (2000); and Hardouvelis, Malliaropulos and Priestley (2006)) is to introduce potential timescale-dependency to the integration process

Investor's portfolio consists of assets with different investment periods and the total return of the portfolio is the sum of these individual components. Thus the return can be represented as

$$
E_{t-1}\left(r_{i, t}\right)=\sum_{k=1}^{p} \eta_{d_{k}} E_{t-1}\left(r_{i, t}\right)^{d_{k}}
$$

where $E_{t-1}\left(r_{i, t}\right)$ is the cumulative expected return of portfolio $i$ at time $t$ and $\eta_{d_{k}}$ denotes the share of each return period $d_{k}(k=1, \ldots, p)$ in the total expected excess returns.

As the level of return comovement may vary across time and differ between return periods, it is measured with dynamic correlation for each timescale separately:

$\operatorname{corr}\left(E_{i, t-1}\left(r_{i, t}\right)^{d_{k}}, E_{j, t-1}\left(r_{j, t}\right)^{d_{k}}\right), i \neq j$, for all $d_{k}, k=1, \ldots, p$.

The U.S. market is used as a numeral for the measures of correlation (in (2): $j=U . S$.). In addition to the BRICs, we study the integration of the leading, major industrialized countries' equity markets (the U.K., Germany and Japan) as well as the impacts of geographical proximity and regional factors by including developed neighboring countries (Canada, Australia and Hong Kong) to our dataset ( $i=$ Brazil, Russia, India, China, the U.K., Germany, Japan, Canada, Australia, Hong Kong). Estimates of the neighboring countries' stock market correlation are expected to facilitate inferences about the potential importance of the regional factors for comovement.

Time-varying stock market comovement is examined using correlation structures between countries for different periods of return: $d_{k}$ : daily $\left(d_{1}\right)$, weekly $\left(d_{2}\right)$, halfmonthly $\left(d_{3}\right)$, monthly $\left(d_{4}\right)$, quarterly $\left(d_{5}\right)$ and semiannual returns $\left(d_{6}\right)$ The return periods are filtered utilizing wavelets and the filtered series are used as an inputs in DCC. The following chapters describe the utilized methods: 1) wavelet transformation and its multiresolution analysis, which decompose the return series into several timescales and 2) dynamic conditional correlation, which measures the time-varying correlation dynamics.

\subsection{Wavelet transform}


Wavelets are small waves that begin at a finite point in time and end at a later finite point in time. They can be seen as an extension of the Fourier analysis and possess some useful properties for decomposing and filtering the data to different frequencies. With this filtering we are able to study the various return layers that constitute the total returns instead of studying the returns from different periods. Wavelets have been largely overlooked in finance and economics with only a few exceptions. Wavelet analysis was introduced to economics by Ramsey and Lampart (1998a, b), who used it to analyze the money-income and money-expenditure relationships. Recently they have been applied by Rua and Nunes (2009), Jammazi and Aloui (2010) and Masih, Alzahrani and Al-Titi (2010).

This paper offers only a very short introduction to the technique; for a more formal presentation, see Daubechies (1992), Percival and Walden (2000) and Gençay, Selçuk and Whitcher (2002). Schleicher (2002) and Crowley (2007) provide a more intuitive approach to the topic with economic applications in mind.

Wavelets have two characteristics that make them useful in signal analysis. First, while Fourier transform decomposes the time series into infinite-length sines and cosines, discarding all time-localization information, wavelet transforms are well localized with respect to both time and scale, which makes them useful in analyzing a variety of nonstationary signals. Second, wavelets can separate a signal into multiresolution components. The wavelet transform techniques split up a signal into a large timescale approximation (coarse approximation) and a collection of fine resolution layers, which capture the finer details of the signal at smaller timescales.

Any function $f(t) \in L^{2}(R)$ that is represented by a wavelet analysis can be built up as a sequence of projections onto father and mother wavelets generated from $\phi$ and $\psi$ through scaling and translation, as follows:

$$
\phi_{j, k}(t)=2^{-j / 2} \phi\left(\frac{t-2^{j} k}{2^{j}}\right)
$$

and

$\psi_{j, k}(t)=2^{-j / 2} \psi\left(\frac{t-2^{j} k}{2^{j}}\right)$,

where $j$ indexes the scale and $k$ indexes the translation. $2^{j}$ is a measure of the scale or the width of the functions $\phi_{J, k}(t)$ and $\psi_{j, k}(t)$. That is, the larger the index $j$, the larger the scale factor $2^{j}$, and thus the function gets shorter and more spread out. The translation parameter $2^{j} k$ is matched to the scale parameter $2^{j}$ in that as the functions $\phi_{J, k}(t)$ and $\psi_{j, k}(t)$ get wider, their translation steps become correspondingly larger.

The wavelet representation of a signal or function $f(t) \in L^{2}(R)$ can now be given as a linear combination of wavelet functions as follows:

$$
f(t)=\sum_{k} s_{J, k} \phi_{J, k}(t)+\sum_{k} d_{J, k} \psi_{J, k}(t)+\sum_{k} d_{J-1, k} \psi_{J-1, k}(t)+\ldots+\sum_{k} d_{1, k} \psi_{1, k}(t),
$$

where the basis functions $\phi_{j, k}(t)$ and $\psi_{j, k}(t)$ are assumed to be orthogonal and the wavelet coefficients $s_{J, k}$ and $d_{j, k}$ are approximated by the following projections $s_{J, k} \approx \int f(t) \phi_{J, k}(t) d t$ 
$d_{j, k} \approx \int f(t) \psi_{j, k}(t) d t$

for $j=1,2, \ldots, J$, where $J$ is the number of multiresolution components and $k$ ranges from 1 to the number of coefficients in the specified component. $s_{j, k}$ are the smooth coefficients that represent the underlying smooth behavior of the series, while $d_{j, k}$ are the detail coefficients that represent the scale deviations from the smooth process. The magnitude of these coefficients reflects a measure of the contribution of the corresponding wavelet function to the total signal. Thus, the father wavelets represent the smooth and low-frequency parts of a signal (the trend) and the mother wavelets describe the detail and high-frequency components (deviations from the trend).

The number of observations controls the number of scales that can be produced. In discrete wavelet transform (DWT), the number of observations has to be dyadic, i.e., the number of observations is an integer power of two and only $j$ scales can be produced given that the number of observations is $N \geq 2^{j}$. In this study, we use 4,096 observations that can easily produce the six scale levels that are used.

This study uses symmlets, which are also known as the least asymmetric wavelets, for the calculations. Based on the recommendations of Percival and Walden (2000) and Crowley (2007), the tap length of the wavelets is chosen to be eight, which should be the most appropriate length for a financial and volatile economic time series. This selection means that the symmlet starts with a width of eight observations for its support, which corresponds to the wavelet used to obtain the $d_{1}$ coefficients.

Figure 1 shows the wavelet decomposition of the U.S. stock returns between the period December 23, 1994 to September 3, 2010 to six scales using symmlets with widths of eight. As can be seen from Figure 1, for the smaller timescales, the return variation is larger because the turbulent periods usually last only for a few days or weeks. However, the major worldwide shocks, such as the dot-com bubble at the beginning of the millennium and the financial crisis of the late-2000s, are clearly visible in all timescales.

\section{Figure 1 here}

\subsection{Dynamic conditional correlation}

The dynamic conditional correlation (DCC) model by Engle (2002) is a generalization of Bollerslev's (1990) constant conditional correlation (CCC) model and offers an effective way to investigate time variations in correlations of asset returns. Previously, it has been used to study correlation structures for example by Chiang, Jeon and Li (2007), Syriopoulos and Roumpis (2009) and Savva (2009). DCC belongs to the family of multivariate GARCH models that are able to capture the time-varying nature of the correlations and can model large covariance matrices ${ }^{4}$. The DCC has many attractive features with which to study highly volatile financial series. It directly considers the heteroskedasticity of the return volatility ${ }^{5}$, allows the inclusion of additional explanatory

\footnotetext{
${ }^{4}$ For a comprehensive presentation of multivariate GARCH models, see Bauwens, Laurent and Rombouts, 2006.

${ }^{5}$ During turmoil periods, the correlation between countries might rise due to increased and transmitted volatility.
} 
variables to the mean equation ${ }^{6}$ and can be used to examine multiple asset returns simultaneously without adding too many parameters ${ }^{7}$.

For each timescale, the return equations are specified as $\operatorname{AR}(p)$-models to take into account the autocorrelation of stock returns

$r_{i, t}=\gamma_{i, 0}+\sum_{j=1}^{p} \gamma_{j} r_{i, t-j}+\varepsilon_{i, t}$,

where $i=1,2, \ldots, n$ and $\varepsilon_{i, t} \mid \Omega_{t-1} \sim N\left(0, H_{t}\right), \Omega_{t-1}$ is the information set at time period $t-1$ and the lag order $p$ is determined by the Schwartz-Bayesian information criterion using a maximum of 10 lags. The multivariate conditional variance is specified as $H_{t}=D_{t} R_{t} D_{t}$

where $D_{t}$ is the $(n \times n)$ diagonal matrix of time-varying conditional standard deviations from univariate GARCH models with $\sqrt{h_{i, t}}$ on the $i$ th diagonal $\left(D_{t}=\operatorname{diag}\left\{\sqrt{h_{i, t}}\right\}\right)$, $i=1,2, \ldots, n$, and $R_{t}$ is the $(n \times n)$ time-varying conditional correlation matrix $\left(R_{t} \equiv\left\{\rho_{i, j}\right\}_{t}\right)$.

Engle (2002) proposed a two-stage estimation for the conditional covariance matrix $H_{t}$. In the first stage, a univariate GARCH model,

$h_{i, t}=\omega_{i}+\varphi_{1} \varepsilon_{i, t-1}^{2}+\varphi_{2} h_{i, t-1}$,

where $i=1,2, \ldots, n$ and $h_{i, t}$ is the conditional variance of the error term $\varepsilon_{i, t}$, is fitted for each of the stock return series, and estimates of $\sqrt{h_{i, t}}$ are obtained. These estimates are subsequently used as inputs in the second stage to calculate the standardized residuals $u_{i, t}=\varepsilon_{i, t} / \sqrt{h_{i, t}}$. Standardized residuals $u_{i, t}$ are used to estimate the DCC parameters that capture the dynamics of the time-varying conditional correlation in the dynamic conditional correlation specification:

$Q_{t}=(1-\alpha-\beta) \bar{Q}+\alpha u_{t-1} u_{t-1}^{\prime}+\beta Q_{t-1}$

where $Q_{t}=\left(q_{i j, t}\right)$ is the $(n \times n)$ time-varying covariance matrix of $u_{t}, \bar{Q}=E\left[u_{t} u_{t}^{\prime}\right]$ is the $(n \times n)$ unconditional covariance matrix of $u_{t}$, and $\alpha$ and $\beta$ are nonnegative scalar parameters that capture the effects of the previous shocks and previous dynamic conditional correlations on current dynamic conditional correlations. Parameters $\alpha$ and $\beta$ satisfy $\alpha+\beta<1$, ensuring that $Q_{t}$ is positive and mean-reverting. This restriction

\footnotetext{
${ }^{6}$ In this study, several autocorrelation coefficients are included in the return equation. A better model may be found for each time scale by including additional variables ex post, but as Longin and Solnik (1995) state, that would be a result of data mining.

${ }^{7}$ Other popular multivariate GARCH models, such as VECH (Bollerslev, Engle and Wooldridge, 1988) and BEKK (Engle and Kroner, 1995), suffer from a rapid increase in the estimated parameters when additional dependent variables are added.
} 
implies that after a shock occurs, the correlation between the underlying assets will return to the long-run unconditional level. ${ }^{8}$ When $\alpha=\beta=0$, the DCC model reduces to CCC.

Because $Q_{t}$ does not generally have ones on the diagonal, it is scaled to obtain a proper correlation matrix $R_{t}$ :

$R_{t}=\left(\operatorname{diag}\left(Q_{t}\right)\right)^{-1 / 2} Q_{t}\left(\operatorname{diag}\left(Q_{t}\right)\right)^{-1 / 2}$

where $\left(\operatorname{diag}\left(Q_{t}\right)\right)^{-1 / 2}=\operatorname{diag}\left(1 / \sqrt{q_{11, t}}, \ldots, 1 / \sqrt{q_{n n, t}}\right)$ is a diagonal matrix involving the square root of the diagonal elements of $Q_{t}$.

$R_{t}$ in equation (12) is a correlation matrix with ones on the diagonal and off-diagonal elements less than one in absolute value, as long as $Q_{t}$ is positive definite. A typical element of $R_{t}$ is of the form

$\rho_{i j, t}=\frac{q_{i j, t}}{\sqrt{q_{i i, t} q_{j j, t}}}$ for $i, j=1,2, \ldots, n$ and $i \neq j$.

In a bivariate case, the time-varying correlation coefficient can be written as

$$
\rho_{12, t}=\frac{(1-\alpha-\beta) \bar{q}_{12}+\alpha u_{1, t-1} u_{2, t-1}+\beta q_{12, t-1}}{\sqrt{\left.\left\{(1-\alpha-\beta) \bar{q}_{11}+\alpha u_{1, t-1}^{2}+\beta q_{11, t-1}\right\} \sqrt{\left\{(1-\alpha-\beta) \bar{q}_{22}+\alpha u_{2, t-1}^{2}+\beta q_{22, t-1}\right.}\right\}}} .
$$

As proposed by Engle (2002), the DCC model can be estimated using a two-stage approach to maximize the log-likelihood function. Let $\theta$ denote the parameters in $D_{t}$ and $\phi$ the parameters in $R_{t}$; the log-likelihood function is then

$l_{t}(\theta, \phi)=\left[-\frac{1}{2} \sum_{t=1}^{T}\left(n \log (2 \pi)+\log \left|D_{t}\right|^{2}+\varepsilon_{t}{ }^{\prime} D_{t}^{-2}\right)\right]+\left[-\frac{1}{2} \sum_{t=1}^{T}\left(\log \left|R_{t}\right|+u_{t}{ }^{\prime} R_{t}^{-1} u_{t}-u_{t}{ }^{\prime} u_{t}\right)\right]$,

where the first part corresponds to the volatility, which is the sum of the individual GARCH likelihoods. The log-likelihood function can be maximized in the first stage over the parameters in $D_{t}$. Given the estimated parameters in the first stage, the second part of the likelihood function, the correlation component, can be maximized to estimate correlation coefficients.

\section{Stock Market Correlations among the BRICs and Developed Economies}

We use the U.S. market as a numeral for the correlations and examine the level of stock market comovement among the BRIC countries as well as the leading, major industrialized economies (the U.K., Germany and Japan) and the developed neighboring countries (Canada, Australia and Hong Kong).

\footnotetext{
${ }^{8}$ A typical element of $Q_{t}$ is given by $q_{i j, t}=(1-\alpha-\beta) \bar{q}_{i j}+\alpha u_{i, t-1} u_{j, t-1}+\beta q_{i j, t-1}$, where $\bar{q}_{i j}$ is the unconditional correlation of $u_{i, t} u_{j, t}$.
} 


\subsection{The Data}

The data used in this research are the most commonly used representative daily closing equity market price indices for the seven developed markets of the U.S. (S\&P 500 Composite Index), Canada (S\&P TSX Composite Index), the U.K. (FTSE 100 Price Index), Germany (DAX 30 Index), Japan (Nikkei 225 Stock Average Index), Australia (S\&P ASX 200) and Hong Kong (Hang Seng) and for the four emerging markets of Brazil (Bovespa Index), Russia (RTS Index), India (BSE 100 Index) and China (Shanghai SE A Share Index $)^{9}$. Canada is added to the sample as a developed market from the American region while Hong Kong enables us to study the differences between Mainland China's markets and the more developed market next to it. Australia is chosen because it represents a western market in Asia and thus could behave differently compared to other markets in the Asian region. The sample period ranges from December 23, 1994 to September 3, 2010, totaling 4,096 observations. The exception is Russia because the RTS Index was launched on September 1, 1995 and thus has only 3,915 observations. As the use of discrete wavelet transform requires that the dataset's length is dyadic (i.e., the number of observations is an integer power of two), the sample mean is used for Russia to expand the series to proper length. All indices are measured in the U.S. dollars and are obtained from Thomson-Datastream.

A well-known and major problem with the use of daily returns across countries is the nonsynchronous periods for the different markets around the globe ${ }^{10}$. This issue is especially important when focusing on links between Asian, European and American markets, as they are not open at the same time. Several studies address this problem by using weekly or monthly data (e.g., Longin and Solnik (1995) and Bekaert, Hodrick and Zhang (2009)), essentially giving up on inspecting higher frequencies. This approach leads to smaller samples that might be problematic for the estimation of time-varying parameters in multivariate models. This problem is avoided in this study as the wavelet analysis decomposes the return series into different timescales, with the smallest scale being 2-4 days.

Stock returns are calculated as the difference of the logarithm of the price index. Because the data originates from different countries, it is inevitable that different holidays are included for each market; thus some data are unavailable. The problem is bypassed by assuming that stock prices stay the same as those on the previous trading day. Thus, the sample for each country consists of all weekdays excluding weekends. This solution is needed to use wavelet multiresolution decomposition because the analysis requires that the data be sampled at equally spaced intervals (Crowley, 2007).

Table 1 presents the descriptive statistics for the stock markets, including mean returns, standard deviations, skewness and kurtosis as well as the Jarque-Bera statistics testing for the normality of returns.

\footnotetext{
${ }^{9}$ Due to the significant limitations to the foreign investors' participation in China's A-share markets, the results were also estimated to the Shanghai SE B Share Index. The results were qualitatively similar with the A-share index. The results are available from the authors.

${ }^{10}$ Martens and Poon (2001) argue that non-synchronous data underestimate the true correlations between stock markets.
} 


\section{Table 1 here}

All markets except Japan show positive average returns over the sample period. It is notable that for each region, the emerging markets have higher mean returns and standard deviations than the developed markets, implying higher expected returns with greater risks. Russia possesses the highest values in both categories, with a mean of $0.069 \%$ and standard deviation of $2.794 \%$ per day, while Japan has the lowest mean of $-0.014 \%$ and the U.S. has the lowest standard deviation of $1.259 \%$. It can also be noted that daily returns are negatively skewed for all markets except for Japan, Hong Kong and China and that all of the return series are leptokurtotic (i.e., peaked relative to the normal distribution and have fat tails). Consequently, all of the series display strong evidence of non-normality as confirmed by the Jarque-Bera statistics. The Augmented Dickey-Fuller test proposes that the return series are stationary.

After calculating the return series for each share index, a wavelet analysis is used to decompose each series into its constituent multiresolution components. To this end, a discrete wavelet transform is applied on the daily return series by sampling the return series at evenly spaced points in time. As such, the return series is transformed from a time domain into a scale domain to elucidate the frequency with which the activity in the time series occurs. In this study, the daily return series are sampled to six scales $(j)$ with symmlets (least asymmetric wavelets) with widths of eight as follows: $d_{1}$ (2-4 days), $d_{2}$ (4-8 days), $d_{3}$ (8-16 days), $d_{4}$ (16-32 days), $d_{5}$ (32-64 days), and $d_{6}$ (64-128 days), and $s_{6}$ which captures the lower frequencies. We also examine the dynamicity of the original daily return series $R$.

\subsection{Volatility modeling}

The GARCH-DCC estimations are carried out using residuals from AR-filtered returns ${ }^{11}$. Since the AR-GARCH structure itself is not a subject of interest in the study and to save space, the results from AR-filtering as well as the GARCH-parameters are not reported here $^{12}$. It can be mentioned from AR-estimates, however, that for those countries which have significant AR structure, the AR(1)-coefficient is always negative and the AR(2)coefficient is positive. As the time scale increases, the AR-coefficients become less and less significant and after $d_{3}$, none of the coefficients are statistically significant and thus the results are estimated with returns without AR-filtration ${ }^{13}$.

As for the GARCH-structure, the coefficients $\varphi_{1}$ and $\varphi_{2}$ measure the ARCH and GARCH effects, respectively. For the original return series, $R$, and for smaller time scales, $d_{1}, d_{2}$ and $d_{3}$ the coefficients are positive and highly significant. For the same return periods the persistency of the volatility, measured by $\varphi_{1}+\varphi_{2}$, varies between 0.85 and 1 indicating that the volatility is time-varying and the GARCH-specification is in

11 The most suitable AR-filtration was chosen based on the Schwarz-Bayesian information criterion (SBIC).

${ }^{12}$ The results are available from the authors.

${ }^{13}$ All the calculations were also estimated with and without appropriate AR-filtrations but the results were alike. 
most cases appropriate although IGARCH could also be used. For higher time scales $\left(d_{4}\right.$, $d_{5}$ and $d_{6}$ ) most of the coefficients are still statistically significant, but the magnitudes of $\varphi_{2}$ are lower than before implying that the volatility is not as persistent for higher scales as it is for smaller scales. In some cases the coefficients are even zero and not statistically signifinicant indicating that the framework is unsuitable for them. This supports the view that the estimations of GARCH models are unreliable with small samples.

\subsection{Dynamic conditional correlation with the U.S.}

Table 2 reports the results from the $\operatorname{DCC}(1,1)$ model in a bivariate framework and the log-likelihood values of the DCC and CCC models, the likelihood-ratio test between them and some descriptive statistics of the correlation dynamics ${ }^{14}$. The estimated parameters $\alpha$ and $\beta$ in the DCC model capture the effects of the lagged standardized shocks $u_{t-1} u_{t-1}^{\prime}$ and the lagged conditional correlations $Q_{t-1}$ on current dynamic conditional correlations. The statistical significance of these coefficients indicates the presence of dynamic (time-varying) equity market correlations. When the parameters $\alpha$ and $\beta$ are zero, the DCC model is reduced to a CCC model.

For all of the estimated coefficients, the estimates are non-negative and for almost all, $\alpha+\beta<1$ indicating that the dynamic correlations move around a constant level and the dynamic process appears to be mean-reverting. For $d_{2}$ in Germany, $d_{3}$ in India and $d_{6}$ in Australia, the sums of the DCC parameters are equal to 1 . Although it is recognized that this is a possible source for model misspecification, it is not considered as a serious problem as it is a result of rounding up. In most of the return series, the estimates are also statistically significant, supporting the presence of a dynamic correlation over time. This finding is especially true for $R, d_{1}, d_{2}, d_{3}$ and $d_{4}$, most of which have the parameter $\beta$ greater than 0.90 implying that the correlation between two markets is time-varying, with a high level of persistence. It is notable, however, that for several Asian markets, the parameters are insignificant or small when compared to other markets. In $R$, Hong Kong has zero $\beta$ parameter and in $d_{1}$ both, India and Hong Kong, have zero $\alpha$ and $\beta$ parameters while China has a small $\beta$ estimate. For $d_{2}$, Japan and Australia have insignificant $\beta$ parameters, and India has zero parameters for $d_{4}$. For $d_{5}$ and $d_{6}$ the dynamicity of the correlation breaks down in several markets, as many $\beta$ parameters are zero and less than half of the markets experience dynamicity in correlation.

\section{Table 2 here}

Figures 2-6 show the development of pairwise correlations between the stock returns of the U.S. and those of Canada, Germany, Japan and the BRICs during the period between December 23, 1994 and September 3, 2010 for $R$ and for the timescales $d_{1}, d_{2}, d_{4}$ and

\footnotetext{
${ }^{14}$ As a robustness check the correlations were also estimated with BEKK model by Engle and Kroner (1995). The results were similar with DCC although with higher standard deviations. The BEKK model estimations are available from the authors.
} 
$d_{6}{ }^{15}$. As can be seen from these figures and the statistics in Table 2, a market's correlation may vary during the whole sample period, albeit its variance can be so small as to render the CCC model appropriate. Although the significance of the parameters provides evidence regarding the dynamicity of the correlation, it is necessary to test it formally. We compare the log-likelihood values of the dynamic and constant correlation models. For this purpose, the CCC model is estimated and its log-likelihood result is compared with the log-likelihood of the DCC model. The null hypothesis of no dynamic conditional correlation is $\alpha=\beta=0$. This is tested using the likelihood-ratio test (LRT) which is asymptotically distributed as $\chi^{2}$ with two degrees of freedom: LRT $=-2$ [LL CCC - LL DCC] $\sim \chi_{2}^{2}$. LRT values are reported on the seventh column of Table 2 . For $R$, the DCC model captures the dynamics better than the CCC model for all equity markets except Hong Kong and China. For $d_{1}$, there is evidence for DCC for all markets except Hong Kong, India and China; in $d_{2}$ for all markets except Japan, Australia, Hong Kong and China; and in $d_{3}$ for Hong Kong and China. This finding is interpreted as evidence that the correlation with the U.S. has remained rather constant in the Asia region with smaller timescales. When the timescale increases, the dynamicity becomes insignificant for other markets too. In the case of $d_{4}$, only Brazil, Japan and Hong Kong; India for $d_{5}$ and only Germany for $d_{6}$ experience dynamic conditional correlation. Accordingly, for the higher timescales, CCC would be sufficient for most of the markets. For portfolio allocation this implies constant benefits.

\section{Figures 2-6 here}

\subsection{Development vs. regional factors}

Figure 3 indicates that in $d_{1}$ at the beginning of the period, all markets except Canada and Brazil experience a rather weak comovement with the U.S., while the Asian regional markets are even negatively correlated with the U.S. It is notable that, while the correlations of the emerging Asian markets such as India and China are negative and almost constant, Japan and Australia have the smallest correlations. These two markets have negative correlations with the U.S. for almost the entire sampling period. It is also notable that the correlations of the European markets (Germany and Russia) have grown rather steadily after 2005 . The results for $d_{1}$ provide evidence that the regional effect is a dominating factor in the correlation determination at a small scale, while the development factor does not have a significant role.

For $d_{2}$ (4-8 days), the correlations are higher for all of the markets. The markets can be divided into highly correlated markets (Canada, Brazil, Germany and the U.K.), moderately correlated markets (Russia, Hong Kong, Australia and India), and mildly correlated markets (Japan and China). At the end of the sample period, the correlation

15 To clarify the figures, some markets are excluded and only the most important regional markets are presented. To save space, the figures are only presented for $d_{1}, d_{2}, d_{4}$ and $d_{6}$. Figures for $d_{3}$ and $d_{5}$ are available from the authors. 
among the highly correlated markets is around $0.60-0.75$, between 0.20 and 0.40 for the moderately correlated and between -0.10 and 0.20 for the mildly correlated markets. The steady rise in correlation during the last five years is now more visible for all other markets except Japan, Australia and China.

The correlations experience substantial dynamicity for $d_{3}$ (8-16 days) scale as the LRT test provides statistically significant results for almost all of the markets. In addition, the strength of the comovement increases and the mean correlations for the U.K. and Germany rise to the same levels as Canada, passing that of Brazil. For each region, the BRIC countries are clearly less correlated with the U.S. than the developed markets.

The differences in stock market interdependencies between the emerging and developed markets start to show for $d_{4}$ and $d_{5}$. Canada, the U.K. and Germany are clearly the most correlated markets with the U.S. during the sample period, with the correlation measuring at almost 0.80 at the end of the period. For $d_{4}$, the correlations of Japan and Australia increase during the sample period and, among others, they jump to a new level during the late-2000s financial crisis. The $d_{4}$ correlations among the BRIC countries are approximately at the same level as the $d_{2}$ correlations. Brazil and Russia are in the same class with Japan and Hong Kong. For $d_{5}$, the correlations are mostly higher than those of smaller scales and remain rather constant for the entire sampling period. The mean of the correlations for the BRIC countries is smaller than that of any of the developed countries, regardless of their region. The results from $d_{4}$ to $d_{5}$ suggest that the development factor, instead of the regional factor, begins to dominate the correlation structure as the timescale increases.

For $d_{6}$, the comovement levels are almost constant for several markets. The developed markets are the most correlated, with the values for the U.K. and Germany being close to 0.90 and those for Canada, Japan and Australia being approximately 0.80 . India's correlation varies substantially and is eventually slightly lower than Hong Kong's, at approximately 0.70 while Brazil's stays rather steady between 0.60 and 0.70 . Russia's is approximately 0.40 . China is clearly the least correlated, with a constant correlation of -0.06. Figure 6 and Table 2 show that the developed markets experience higher comovement with the U.S. than the BRIC countries, with only Brazil reaching the same level as the developed markets.

As far as the potential portfolio diversification benefits are concerned, for the U.S. short-term investors, Japan and Australia provide the best diversification benefits at the daily $\left(d_{1}\right)$ level. However, when the timescale begins to increase, the benefits also disappear, although China's correlation with the U.S. stays rather small for all of the tested timescales. It can also be noted that the developed markets follow the long-term trends of the U.S. more closely than the BRIC countries. Nonetheless, at shorter timescales, Japan, Australia and Hong Kong have generally lower correlations with the U.S. than Brazil, Russia and India. Accordingly, it can be concluded that at lower timescales, regional effects dominate in correlation structure, while the development factors start to play a role for longer scales. The results also suggest that clustering the BRICs into one homogenous group is not justified.

\subsection{Testing for correlation trends}


The DCC framework presents the correlation dynamics as a function of time, which enables us to study the trends in comovement with a simple linear and nonparametric trend test. We formally test the long-run behavior of the correlation by using Perron and Yabu's (2009) method. Our results are consistent with the findings of Bekaert et al. (2009) that the correlations generally have not increased during the sample period, as only a few markets have experienced growing trends and the slope coefficient for most of them is insignificantly small. ${ }^{16}$

\subsection{Tests for the Robustness of the Results}

\subsubsection{MODWT results}

As for a robustness check, the results are also estimated using the maximal overlap discrete wavelet transform (MODWT). MODWT does not subsample the filtered outputs and relaxes the orthogonality property needed in DWT. ${ }^{17}$

The results are largely immune to the method of estimation. The correlation means are qualitatively similar regardless of the method of estimation, although MODWT produces higher standard deviations, higher maximums and smaller minimums. ${ }^{18}$ As a result, the DCC is more desirable in case of MODWT-filtered returns than CCC. However, our fundamental results regarding the stock market comovement in the BRIC countries still apply.

\subsubsection{Dividend adjusted returns}

The original results were estimated using price indices that exclude dividends. This approach is a potential source of misspecification, especially for the lower scales. To evaluate the importance of the dividends for BRICs stock market comovement, wavelets and DCCs were also estimated using the MSCI Global Investable Market Indices (GIMI) family on total returns, which comprise both the price performances and the dividend payments. Unfortunately, this procedure produces some data limitations because for Russia, the index is only available from August $20^{\text {th }}$, 1997. In addition, the index for China does include the major Chinese indices available for foreign investors, China B and the Mainland China related indices of Hong Kong, China $\mathrm{H}$ and Red Chips, but omits the China A shares. The available data period for the MSCI GIMI China A-share index, in turn, is too short for a precise analysis.

Overall, the results were broadly immune to the inclusion of dividends with the exception of China, which comovement became significantly higher for all scales higher than $d_{2}$ and became rather similar with that of India ${ }^{19}$. The Chinese results, however, could be mostly due to the composition of the China Investable index.

\footnotetext{
${ }^{16}$ More accurate results for the Perron-Yabu trend test are available from the authors.

${ }^{17}$ For a thorough discussion between the MODWT and DWT, see Percival and Walden (2000).

${ }^{18}$ To save space, the MODWT-DCC results are not presented here but are available from the authors.

${ }^{19}$ Results are available from the authors.
} 


\section{Conclusions}

This paper examines the differences between several return periods by studying the asset return comovement of the so-called BRIC countries (Brazil, Russia, India and China) with respect to the U.S. market for several timescales. We study the stock market dynamics of the major developed markets (the U.K., Germany, and Japan) as well the neighboring countries (Canada, Australia and Hong Kong) to capture the potential effects of geographical proximity and regional factors for the comovement dynamics. Our results lend support to the necessity of modeling international stock market dynamicity using time-varying estimation methods.

The analysis is performed using wavelet analysis, which decomposes the return series into a large timescale approximation and a collection of finer resolution layers, which capture the finer details of the signal. The timescales can be examined individually, which enables us to study the risks for both short- and long-term investors. To capture the time-varying features of the stock return comovement, the relationship between asset returns is studied with pairwise dynamic conditional correlation with the U.S. market. This setting allows us to study whether there are differences between the regions, how the level of development of the market affects the correlations and has the correlation increased.

In part, our results are in line with the findings of the previous studies, but due to the flexibility of wavelet analysis and DCC, we were also able to provide some new and novel results regarding the comovement of the stock market and potential benefits of international portfolio diversification. The results indicate that the dynamicity and strength of the return comovement depend on the timescale as correlation increases and its dynamicity decreases when the timescale increases for all the markets.

Our results lend support for the benefits of international portfolio diversification both within the BRICs and between the BRICs and the industrial economies. For the smaller timescales, our results support the conclusions of Groenen and Frances (2000) that the stock markets can be divided into three clusters: Asia, Europe and America. The correlation structures for these scales vary substantially during the sample period and differ significantly between the markets. As the timescale increases, the variations in the comovement levels deteriorate and become insignificantly small for almost all of the markets and the gaps between the market correlations decrease. In accordance with Bekaert et al. (2009), we do not generally detect increases in the correlation trends for any of the timescales. For the lower scales (i.e. for the higher frequencies), regional factors dominate as the American region experiences the highest comovement, while the Asian region and especially the markets of Japan, Australia and China are very weakly correlated with the U.S. However, for the higher scales (i.e. for the lower frequencies), the level of economic development begins to dominate over regional factors as the developed markets are more correlated with the U.S. than the BRICs. Thus, for higher scales, the diversification benefits are almost lost for the developed markets, while emerging markets, and particularly China, still provide a fruitful ground for international diversification. Our results also show, that in terms of correlation with the U.S., BRICs cannot be clustered into a single group. 
These findings lead us to conclude that the developed markets share similar longterm return fundamentals even though their short-term fundamentals might differ. The results stress the importance of the time- and frequency-varying properties of the stock return comovements for international portfolio design. To analyze the determination of the correlations with different timescales among the stock markets more precisely, a formal investigation on the explanatory variables of returns, as well as the effects of industrial factors, is needed. This work is, however, left for future research.

\section{Acknowledgements}

We thank Juhani Raatikainen, Kashif Saleem, Pekka Mannonen, Vance L. Martin, Patrick M. Crowley, Anatoly Peresetsky and seminar participants of the $33^{\text {rd }}$ Annual Meeting of the Finnish Economic Association in Oulu, $15^{\text {th }}$ annual International Conference on Macroeconomical Analysis and International Finance in Rethymno and $9^{\text {th }}$ INFINITI Conference on International Finance in Dublin for the helpful discussions and comments. 


\section{References}

Bauwens, L., Laurent S. and Rombouts, J.V.K., 2006. Multivariate GARCH models: A survey, Journal of Applied Econometrics 21, 79-109.

Bekaert, G. and Harvey, C.R., 1995. Time-varying world market integration, Journal of Finance 50, 403-444.

Bekaert, G. and Harvey, C.R., 1997. Emerging equity market volatility, Journal of Financial Economics 43, 29-77.

Bekaert, G., Harvey C.R. and Ng, A, 2005. Market integration and contagion, Journal of Business, 78, 30-69.

Bekaert, G., Hodrick, R.J. and Zhang, X., 2009. International stock return comovements, Journal of Finance 64, 2591-2626.

Bhar, R. and Nikolova, B., 2009. Return, volatility spillovers and dynamic correlation in the BRIC equity markets: An analysis using a bivariate EGARCH framework, Global Finance Journal 19, 203-218.

Black, F., 1974. International capital market equilibrium with investment barriers, Journal of Financial Economics 1, 337-352.

Bollerslev, T., Engle, R. and Wooldridge, J., 1988. A capital asset pricing model with time varying covariances, Journal of Political Economy 96, 116-131.

Bollerslev, T., 1990. Modelling the coherence in short-run nominal exchange rates: a multivariate generalized ARCH model, Review of Economics and Statistics 72, 498-505

Carrieri, F., Errunza, V. and Hogan K. 2007. Characterizing World Market Integration, Journal of Financial and Quantitative Analysis 42, 915-940.

Carrieri, F., Errunza, V. and Sarkissian S., 2004. Industry risk and market integration, Management Science, 50, 207-221.

Chan, K.C., Karolyi, G.A. and Stulz, R.M., 1992. Global financial markets and the risk premium on U.S. equity, Journal of Financial Economics 32, 137-168.

Chiang, T.C., Jeon, B.N. and Li, H., 2007. Dynamic correlation analysis of financial contagion: Evidence from Asian markets, Journal of International Money and Finance 26, 1206-1228.

Cooper, I.A. and Kaplanis, E., 2000. Partially segmented international capital markets and international capital budgeting, Journal of International Money and Finance 19, 309329. 
Crowley, P. and Lee, J., 2005. Decomposing the co-movement of the business cycle: a time-frequency analysis of growth cycles in euro area, Research Discussion Papers 12, Bank of Finland.

Crowley, P., 2007. A guide to wavelets for economist, Journal of Economic Surveys 21, 207-267.

Cuadro-Sáez, L., Fratzcher, M. and Thimann, C., 2009. The transmission of emerging market shocks to global equity markets, Journal of Empirical Finance 16, 2-17.

Daubechies, I., 1992. Ten lectures on wavelets, Montpelier, VT: Capital City Press.

De Jong, F. and de Roon F.A., 2005. Time-varying market integration and expected returns in emerging markets, Journal of Financial Economics 78, 583-613.

Dumas, B., Harvey, C.R. and Ruiz, P., 2003. Are correlations of stock returns justified by subsequent changes in national output? Journal of International Money and Finance 22, 777-811.

Engle, R. and Kroner, K., 1995. Multivariate simultaneous generalized ARCH. Econometric Theory 11, 122-150.

Engle, R., 2002. Dynamic conditional correlation: a simple class of multivariate generalized autoregressive conditional heteroskedasticity models, Journal of Business and Economic Statistics 20, 339-350.

Errunza, V., and Losq, E., 1985. International asset pricing under mild segmentation: Theory and test, Journal of Finance 40, 105-124.

Eun, C.S. and Janakiramanan S., 1986. A model of international asset pricing with a constraint on foreign equity ownership, Journal of Finance 40, 105-124.

Foerster, S., and Karolyi, A., 1999. The effects of market segmentation and investor recognition on asset prices: evidence from foreign stock listing in US, Journal of Finance 54, 981-1014.

Gençay, R., Selçuk, F. and Whitcher, B., 2002. An introduction to wavelets and other filtering methods in finance and economics, Academic Press.

Groenen, P.J.F. and Franses, P.H., 2000. Vizualizing time-varying correlations across stock markets, Journal of Empirical Finance 7, 155-172.

Hardouvelis, G.A., Mallirapulos R. and Priestley R., 2006. EMU and European stock market integration, Journal of Business 79, 365-392. 
Jammazi, R. and Aloui, C., 2010. Wavelet decomposition and regime shifts: Assessing the effects of crude oil shocks on stock market returns, Energy Policy 38, 1415-1435.

Korajczyk R.A., and Viallet, C.J., 1989. An Empirical investigation of international asset pricing. Review of Financial Studies 2, 553-586.

Longin, F. and Solnik, B., 1995. Is the correlation in international equity returns constant: 1960-1990?, Journal of International Money and Finance 14, 3-26.

Martens, M. and Poon, S., 2001. Returns synchronization and daily correlation dynamics between international stock markets, Journal of Banking and Finance 25, 1805-1827.

Masih, M, Alzahrani, M. and Al-Titi, O., 2010. Systematic risk and time scales: New evidence from an application of wavelet approach to the emerging Gulf stock markets, International Review of Financial Analysis 19, 10-18.

Morana, C. and Beltratti, A., 2008. Comovements in international stock markets, Journal of International Financial Markets, Institutions and Money 18, 31-45.

O’Neill, J., Wilson, D., Purushothaman, R. and Stupnytska, A., 2005. How solid are the BRICs? Goldman Sachs Global Economic Paper No. 134

Percival, D. and Walden, A., 2000. Wavelet methods for time series analysis, Cambridge University Press.

Perron, P. and Yabu, T., 2009. Estimating deterministic trends with an integrated or stationary noise component, Journal of Econometrics 151, 56-69.

Pukthuanthong, K. and Roll, R., 2009. Global market integration: An alternative measure and its application, Journal of Financial Economics 94, 214-232.

Ramsey, J. and Lampart, C., 1998a. The decomposition of economic relationships by time scale using wavelets: Expenditure and income, Studies in Nonlinear Dynamics and Econometrics 3, 23-42.

Ramsey, J. and Lampart, C., 1998b. Decomposition of economic relationships by timescale using wavelets, Macroeconomic Dynamics 2, 49-71.

Rua, A. and Nunes, L.C., 2009. International comovement of stock market returns: A wavelet analysis, Journal of Empirical Finance 16, 632-639.

Savva, C.S., 2009. International stock market interactions and conditional correlations, Journal of International Financial Markets, Institutions and Money 19, 645-661.

Schleicher, C., 2002. An introduction to wavelets for economists. Working Paper 2002-3, Bank of Canada, Ottawa, Canada. 
Stulz R.M., 1981. A model of international asset pricing, Journal of Financial Economics 9, 383-406.

Syriopoulos, T. and Roumpis, E., 2009. Dynamic correlations and volatility effects in the Balkan equity markets, Journal of Internation Financial Markets, Institutions and Money 19, 565-587.

Wilson, D. and Purushothaman, R., 2003. Dreaming with BRICs: The path to 2050, Goldman Sachs Global Economic Paper No. 99 
Figures and tables

Figure 1. The U.S. returns and LA (8) wavelet transform for 6 scales
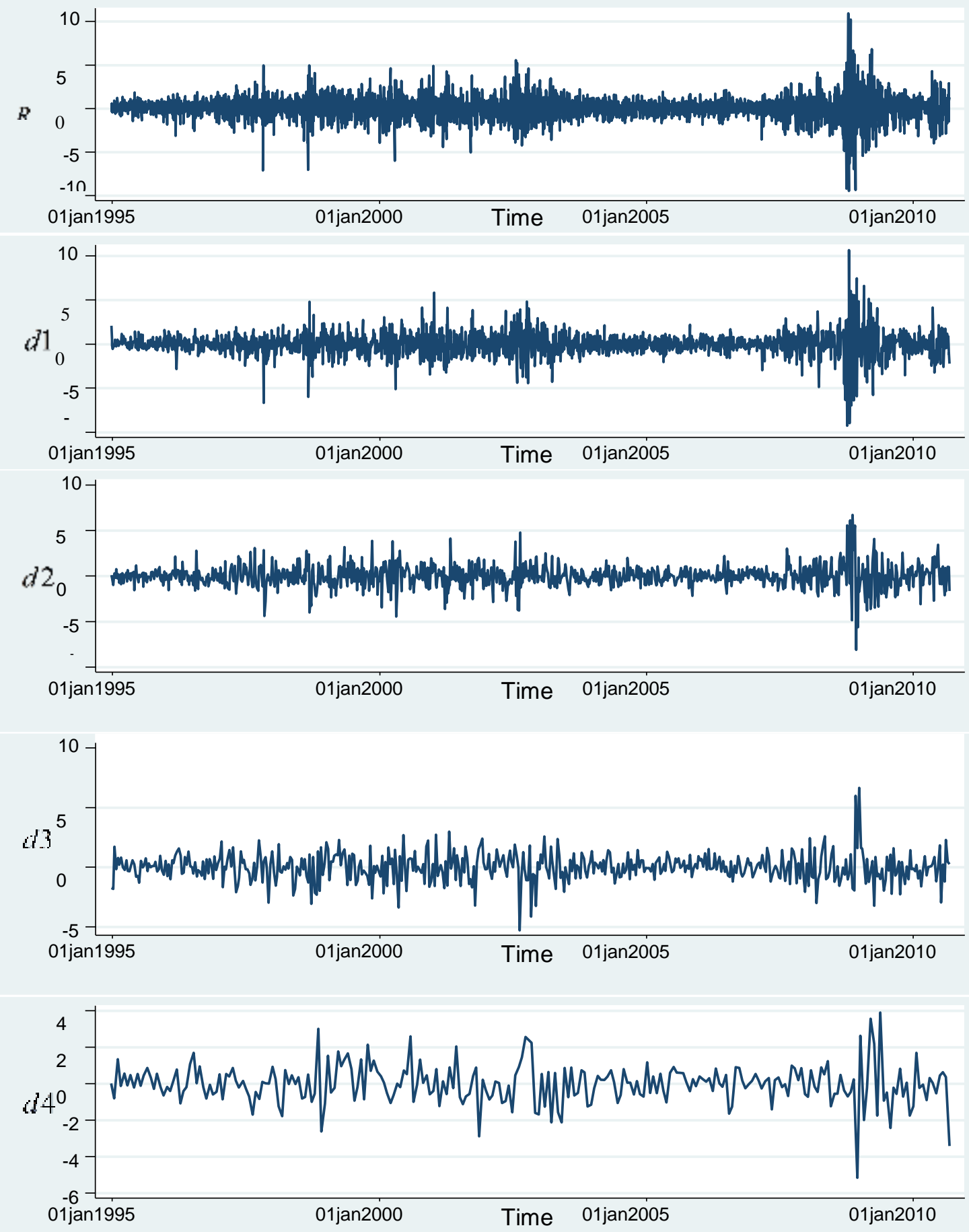

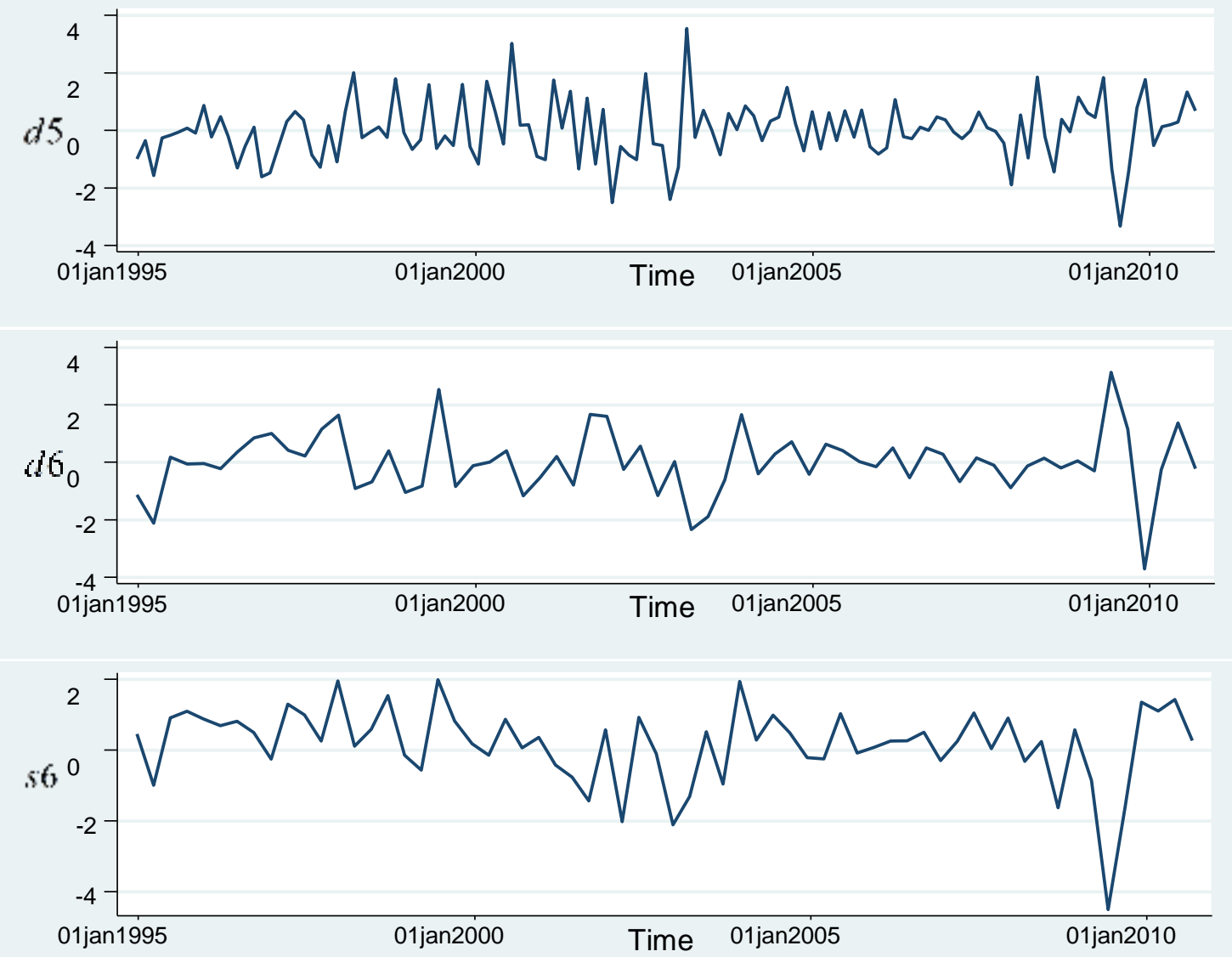
Figure 2. DCCs with the U.S. Dec. 23, 1994 - Sep. 3, 2010

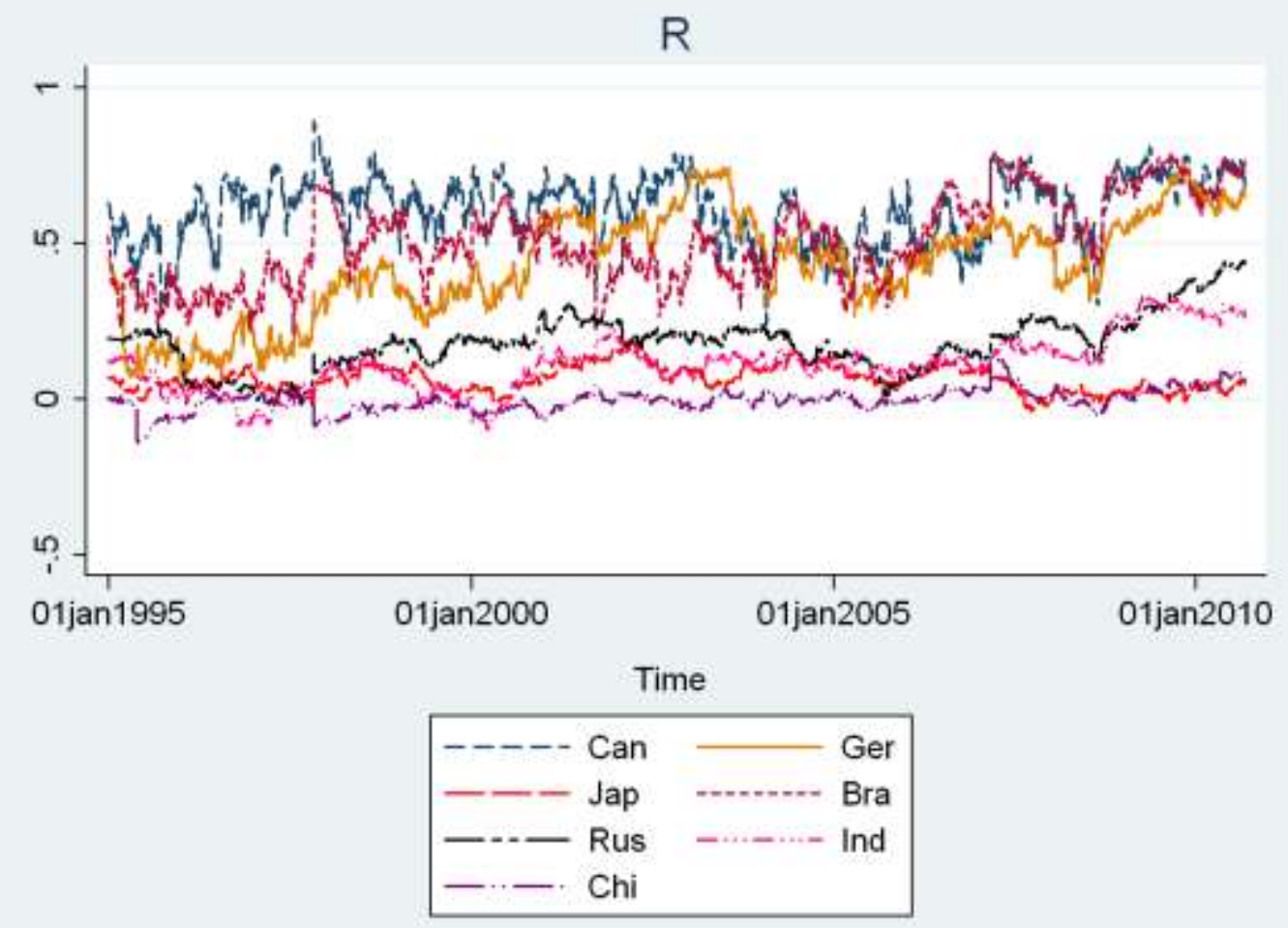

Figure 3. D1 DCCs with the U.S. Dec. 23, 1994 - Sep. 3, 2010

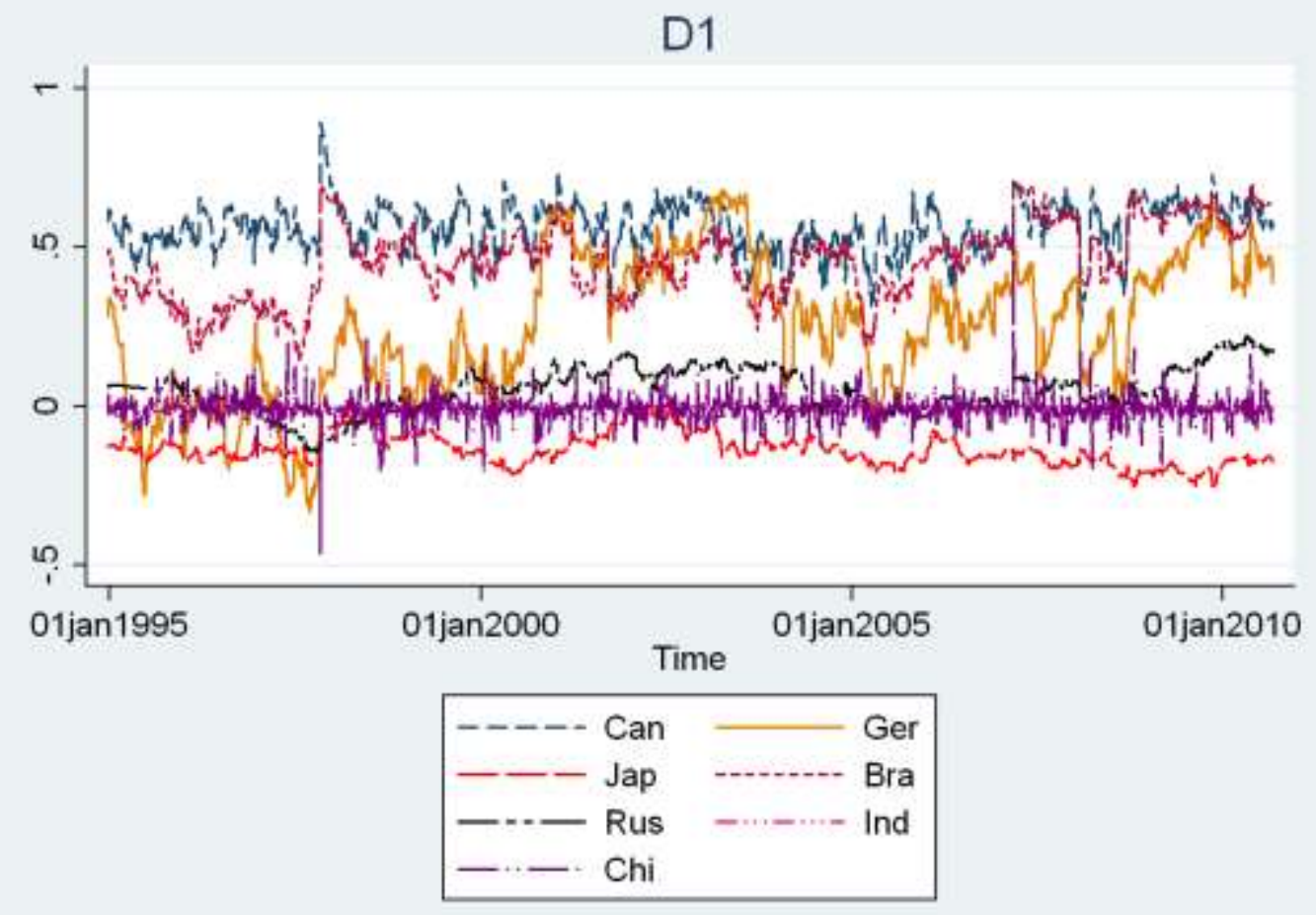


Figure 4. D2 DCCs with the U.S. Dec. 23, 1994 - Sep. 3, 2010

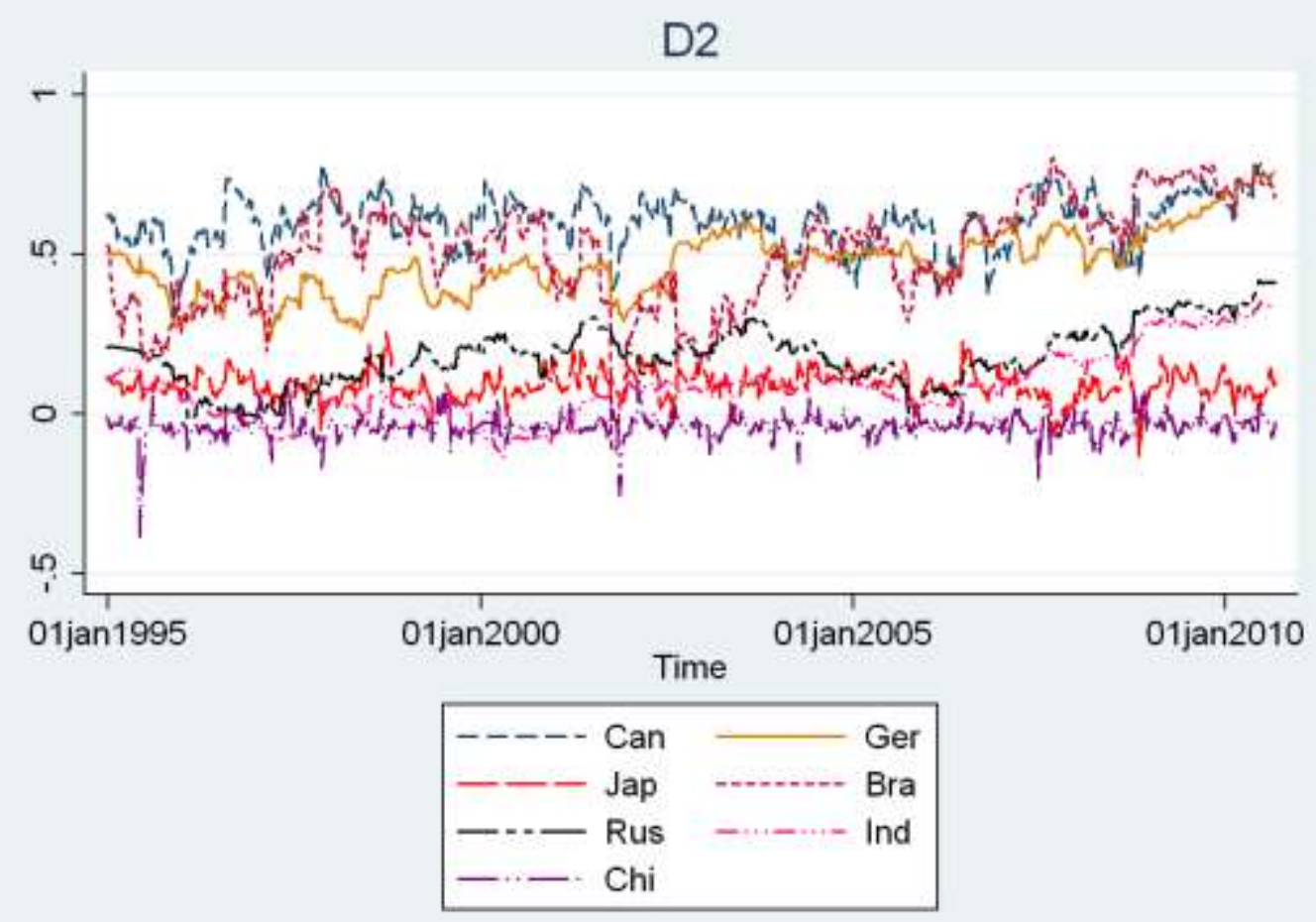

Figure 5. D4 DCCs with the U.S. Dec. 23, 1994 - Sep. 3, 2010

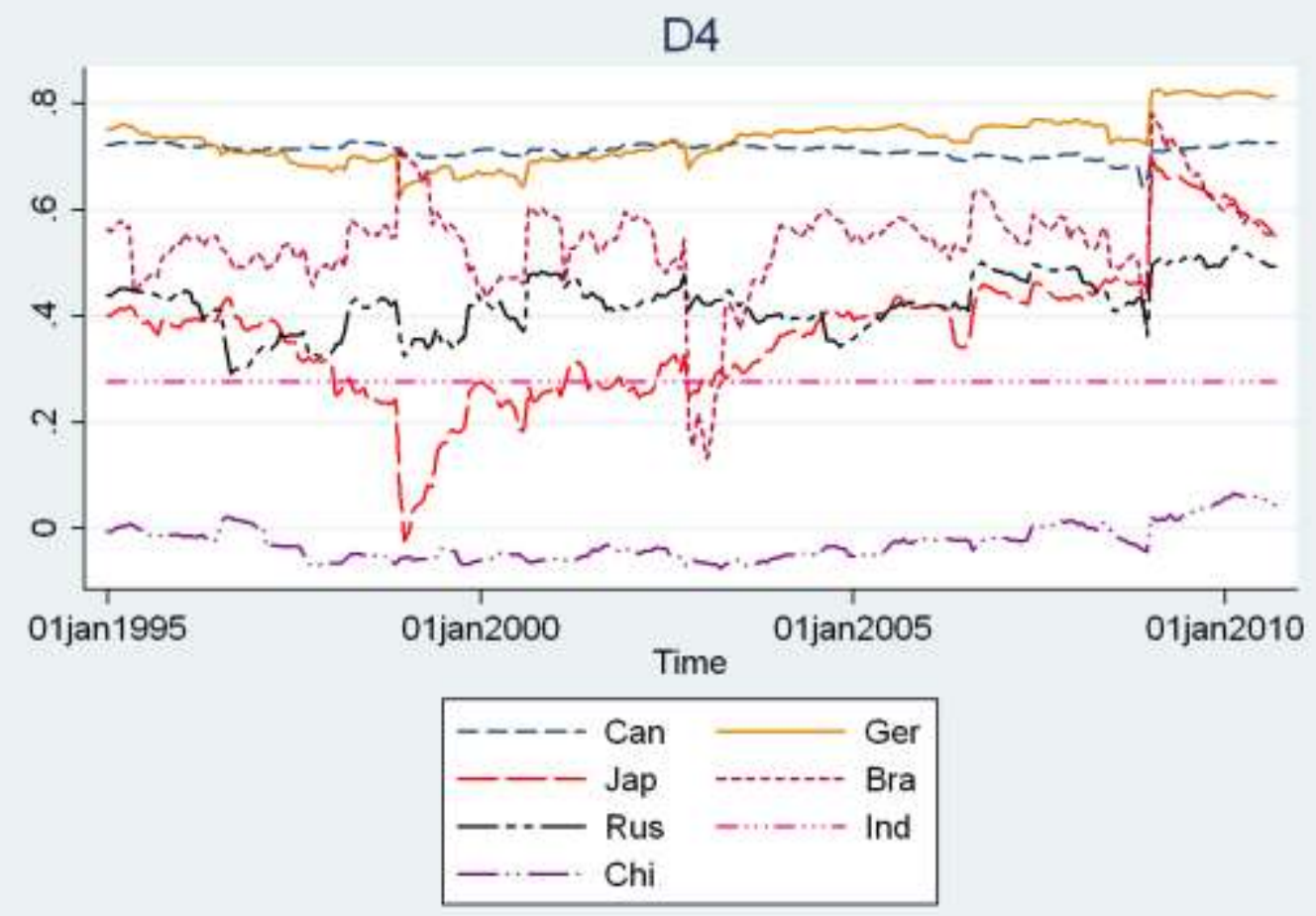


Figure 6. D2 DCCs with the U.S. Dec. 23, 1994 - Sep. 3, 2010

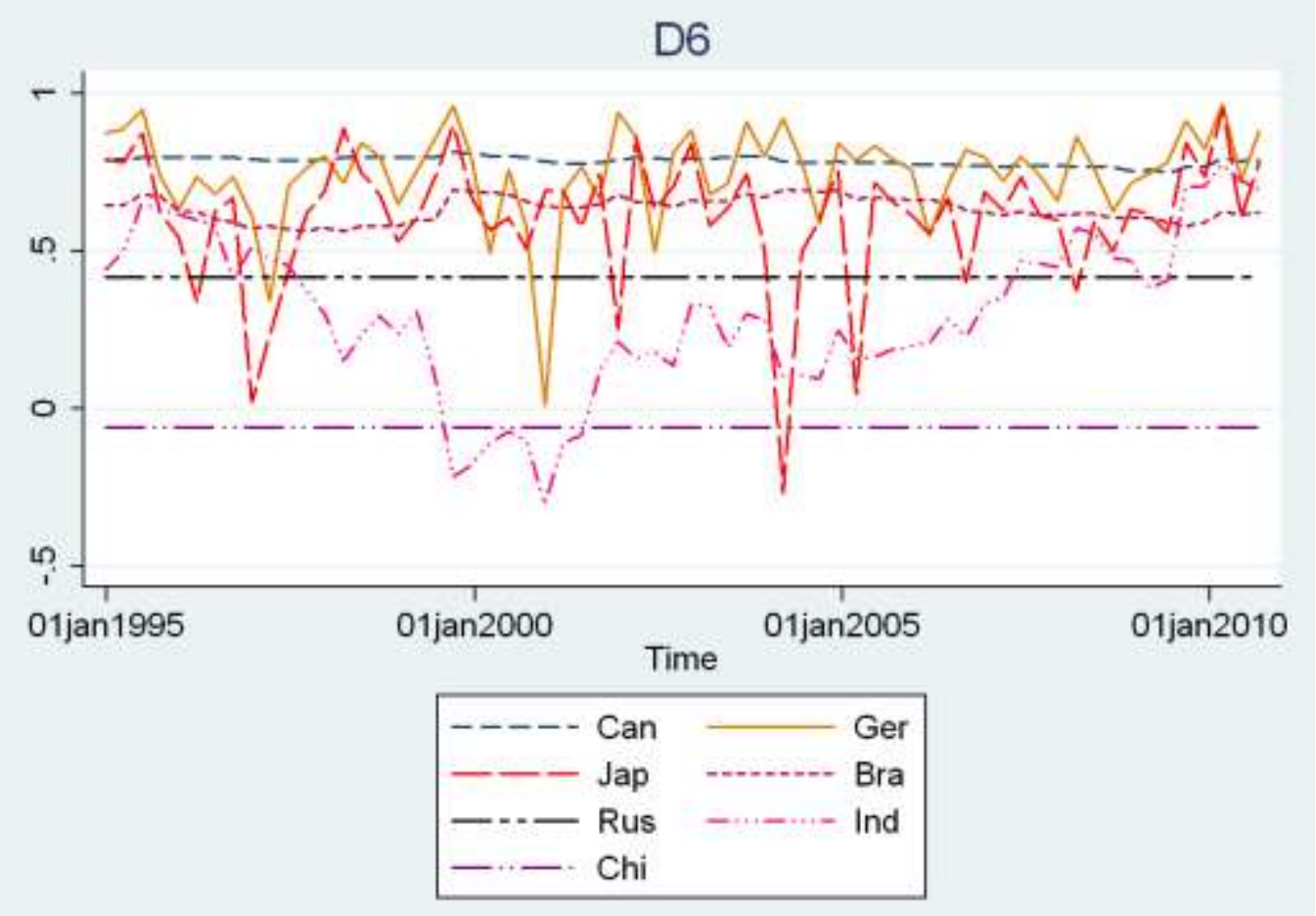

Table 1. Descriptive statistics

\begin{tabular}{llllllll}
\hline Share Index & $\mathrm{N}$ & Mean & $\mathrm{SD}$ & Skewness & Kurtosis & Jarque-Bera & ADF \\
\hline the U.S. & 4096 & 0.021 & 1.259 & -0.200 & 11.267 & 21693.35 & -68.536 \\
Canada & 4096 & 0.033 & 1.369 & -0.878 & 13.826 & 33150.12 & -59.244 \\
Brazil & 4096 & 0.050 & 2.695 & -0.079 & 9.800 & 16394.01 & -59.291 \\
the U.K. & 4096 & 0.014 & 1.349 & -0.093 & 12.626 & 27214.68 & -65.248 \\
Germany & 4096 & 0.027 & 1.600 & -0.059 & 8.131 & 11286.57 & -64.858 \\
Russia & 3915 & 0.069 & 2.794 & -0.441 & 10.550 & 18281.99 & -55.142 \\
Japan & 4096 & -0.014 & 1.633 & 0.054 & 7.004 & 8375.282 & -68.506 \\
Australia & 4096 & 0.026 & 1.447 & -0.911 & 14.586 & 36876.02 & -63.171 \\
Hong Kong & 4096 & 0.022 & 1.738 & 0.125 & 13.049 & 29071.95 & -64.647 \\
India & 4096 & 0.031 & 1.796 & -0.140 & 9.293 & 14752.27 & -57.962 \\
China & 4096 & 0.039 & 1.867 & 0.473 & 21.126 & 76321.48 & -63.139
\end{tabular}

Notes: The table summarizes the statistics of mean, standard deviation, minimum, maximum, skewness, kurtosis, the Jarque-Bera normality test and the Augmented Dickey-Fuller (ADF) unit root test of the market returns. The null hypothesis of a unit root is rejected in the ADF test with $5 \%$ and $1 \%$ critical values of -2.860 and -3.430 , respectively. 
Table 2. Parameter estimates of the bivariate DCC $(1,1)$ models with the U.S. equity market

\begin{tabular}{|c|c|c|c|c|c|c|c|c|c|c|}
\hline \multicolumn{11}{|c|}{$R: 4096$ observations } \\
\hline & $\alpha$ & $\beta$ & $\alpha+\beta$ & DCC LL & CCC LL & LRT & Mean & S.D. & Min & $\operatorname{Max}$ \\
\hline Canada & $\begin{array}{l}0.0298 * * * \\
(0.0000)\end{array}$ & $\begin{array}{l}0.9555 * * * \\
(0.0001)\end{array}$ & 0.9853 & -10985.90 & -11060.97 & $150.14 * * *$ & 0.609 & 0.108 & 0.238 & 0.894 \\
\hline Brazil & $\begin{array}{l}0.0176 * * * \\
(0.0000)\end{array}$ & $\begin{array}{l}0.9795 * * * \\
(0.0000)\end{array}$ & 0.9971 & -14385.27 & -14472.27 & $174.00 * * *$ & 0.507 & 0.138 & 0.207 & 0.792 \\
\hline the U.K. & $\begin{array}{l}0.0063 * * * \\
(0.0000)\end{array}$ & $\begin{array}{l}0.9915 * * * \\
(0.0000)\end{array}$ & 0.9978 & -11617.99 & -11637.75 & $39.51 * * *$ & 0.409 & 0.077 & 0.231 & 0.641 \\
\hline Germany & $\begin{array}{l}0.0143 * * * \\
(0.0000)\end{array}$ & $\begin{array}{l}0.9839 * * * \\
(0.0000)\end{array}$ & 0.9982 & -12332.99 & -12429.11 & $192.24 * * *$ & 0.430 & 0.167 & 0.066 & 0.747 \\
\hline Russia & $\begin{array}{l}0.0051 * * * \\
(0.0000)\end{array}$ & $\begin{array}{l}0.9943 * * * \\
(0.0000)\end{array}$ & 0.9994 & -14598.47 & -14619.85 & $42.77 * * *$ & 0.180 & 0.089 & -0.021 & 0.443 \\
\hline Japan & $\begin{array}{l}0.0043 * * * \\
(0.0000)\end{array}$ & $\begin{array}{l}0.9902 * * * \\
(0.0000)\end{array}$ & 0.9945 & -13310.95 & -13314.88 & $7.86^{* *}$ & 0.064 & 0.042 & -0.042 & 0.185 \\
\hline Australia & $\begin{array}{l}0.0060 * * * \\
(0.0000)\end{array}$ & $\begin{array}{l}0.9891 * * * \\
(0.0003)\end{array}$ & 0.9951 & -12313.41 & -12320.25 & $13.68 * * *$ & 0.149 & 0.056 & 0.026 & 0.333 \\
\hline Hong Kong & $\begin{array}{l}0.0115 * * * \\
(0.0004)\end{array}$ & $\begin{array}{l}0.0000 \\
(0.1933)\end{array}$ & 0.0115 & -13058.01 & -13058.36 & 0.68 & 0.163 & 0.011 & 0.072 & 0.265 \\
\hline India & $\begin{array}{l}0.0058 * * * \\
(0.0000)\end{array}$ & $\begin{array}{l}0.9925 * * * \\
(0.0000)\end{array}$ & 0.9983 & -13474.72 & -13493.44 & $37.44 * * *$ & 0.110 & 0.089 & -0.097 & 0.335 \\
\hline China & $\begin{array}{l}0.0038^{* * * *} \\
(0.0000)\end{array}$ & $\begin{array}{l}0.9897 * * * \\
(0.0001)\end{array}$ & 0.9935 & -13756.27 & -13758.45 & 4.37 & -0.004 & 0.037 & -0.141 & 0.137 \\
\hline \multicolumn{11}{|c|}{$d_{1}: 2048$ observations } \\
\hline & $\alpha$ & $\beta$ & $\alpha+\beta$ & DCC LL & CCC LL & LRT & Mean & S.D. & Min & $\operatorname{Max}$ \\
\hline Canada & $\begin{array}{l}0.0392 * * * \\
(0.0002)\end{array}$ & $\begin{array}{l}0.8922 * * * \\
(0.0031)\end{array}$ & 0.9314 & -5599.40 & -5617.48 & $36.16^{* * *}$ & 0.560 & 0.079 & 0.263 & 0.894 \\
\hline Brazil & $\begin{array}{l}0.0217 * * * \\
(0.0001)\end{array}$ & $\begin{array}{l}0.9657 * * * \\
(0.0003)\end{array}$ & 0.9874 & -7315.70 & -7339.35 & $47.31 * * *$ & 0.456 & 0.118 & 0.135 & 0.705 \\
\hline the U.K. & $\begin{array}{l}0.0082 * * * \\
(0.0001)\end{array}$ & $\begin{array}{l}0.9858 * * * \\
(0.0004)\end{array}$ & 0.9940 & -6129.65 & -6135.69 & $12.09 * * *$ & 0.212 & 0.070 & 0.066 & 0.458 \\
\hline Germany & $\begin{array}{l}0.0314 * * * \\
(0.0001)\end{array}$ & $\begin{array}{l}0.9603 \text { *** } \\
(0.0001)\end{array}$ & 0.9918 & -6460.04 & -6519.22 & $118.37 * * *$ & 0.246 & 0.221 & -0.337 & 0.681 \\
\hline Russia & $\begin{array}{l}0.0074 * * * \\
(0.0000)\end{array}$ & $\begin{array}{l}0.9864 * * * \\
(0.0000)\end{array}$ & 0.9937 & -7446.57 & -7453.92 & $14.70^{* * * *}$ & 0.051 & 0.071 & -0.146 & 0.221 \\
\hline Japan & $\begin{array}{l}0.0068 * * * \\
(0.0000)\end{array}$ & $\begin{array}{l}0.9840 * * * \\
(0.0001)\end{array}$ & 0.9908 & -6804.02 & -6807.17 & $6.29 * *$ & -0.138 & 0.050 & -0.257 & -0.004 \\
\hline Australia & $\begin{array}{l}0.0170 * * * \\
(0.0001)\end{array}$ & $\begin{array}{l}0.9373 \text { *** } \\
(0.0023)\end{array}$ & 0.9542 & -6216.36 & -6220.54 & $8.36^{* *}$ & -0.137 & 0.061 & -0.294 & 0.140 \\
\hline Hong Kong & $\begin{array}{l}0.0000 \\
(0.0000)\end{array}$ & $\begin{array}{l}0.0000 \\
(0.1072)\end{array}$ & 0.0000 & -6635.50 & -6635.50 & 0.00 & -0.088 & 0.000 & -0.088 & -0.088 \\
\hline India & $\begin{array}{l}0.0000 \\
(0.0000)\end{array}$ & $\begin{array}{l}0.0000 \\
(0.5982)\end{array}$ & 0.0000 & -6770.91 & -6770.91 & 0.00 & -0.005 & 0.000 & -0.005 & -0.005 \\
\hline China & $\begin{array}{l}0.0433 * * * \\
(0.0005)\end{array}$ & $\begin{array}{l}0.1192 * * \\
(0.0683)\end{array}$ & 0.1625 & -6942.36 & -6944.35 & 3.99 & -0.010 & 0.041 & -0.466 & 0.576 \\
\hline
\end{tabular}

$d_{2}: 1024$ observations 


\begin{tabular}{|c|c|c|c|c|c|c|c|c|c|c|}
\hline & $\alpha$ & $\beta$ & $\alpha+\beta$ & DCC LL & CCC LL & LRT & Mean & S.D. & Min & Max \\
\hline Canada & $\begin{array}{l}0.0429 * * * \\
(0.0004)\end{array}$ & $\begin{array}{l}0.9019 * * * \\
(0.0013)\end{array}$ & 0.9447 & -2872.02 & -2880.89 & $17.74 * * *$ & 0.602 & 0.081 & 0.295 & 0.784 \\
\hline Brazil & $\begin{array}{l}0.0415 * * * \\
(0.0004)\end{array}$ & $\begin{array}{l}0.9471 * * * \\
(0.0007)\end{array}$ & 0.9887 & -3757.26 & -3786.07 & $57.63 * * *$ & 0.501 & 0.167 & -0.118 & 0.801 \\
\hline the U.K. & $\begin{array}{l}0.0496 * * * \\
(0.0005)\end{array}$ & $\begin{array}{l}0.8389 * * * \\
(0.0038)\end{array}$ & 0.8886 & -2944.18 & -2951.25 & $14.15 * * *$ & 0.488 & 0.081 & 0.174 & 0.701 \\
\hline Germany & $\begin{array}{l}0.0171 * * * \\
(0.0007)\end{array}$ & $\begin{array}{l}0.9829 * * * \\
(0.0019)\end{array}$ & 1.0000 & -3127.12 & -3139.62 & $25.00 * * *$ & 0.473 & 0.105 & 0.228 & 0.759 \\
\hline Russia & $\begin{array}{l}0.0115 * * * \\
(0.0000)\end{array}$ & $\begin{array}{l}0.9847 * * * \\
(0.0001)\end{array}$ & 0.9963 & -3815.32 & -3819.82 & $8.99 * *$ & 0.182 & 0.092 & -0.015 & 0.418 \\
\hline Japan & $\begin{array}{l}0.0252 * * * \\
(0.0020)\end{array}$ & $\begin{array}{l}0.8251 \\
(0.7107)\end{array}$ & 0.8503 & -3415.01 & -3416.75 & 3.48 & 0.087 & 0.044 & -0.135 & 0.253 \\
\hline Australia & $\begin{array}{l}0.0108 * * * \\
(0.0012)\end{array}$ & $\begin{array}{l}0.0000 \\
(8.9834)\end{array}$ & 0.0108 & -3177.08 & -3177.17 & 0.18 & 0.245 & 0.010 & 0.182 & 0.302 \\
\hline Hong Kong & $\begin{array}{l}0.0085 * * * \\
(0.0000)\end{array}$ & $\begin{array}{l}0.9872 * * * \\
(0.0001)\end{array}$ & 0.9957 & -3322.78 & -3324.67 & 3.77 & 0.199 & 0.058 & 0.049 & 0.337 \\
\hline India & $\begin{array}{l}0.0095 * * * \\
(0.0000)\end{array}$ & $\begin{array}{l}0.9872 * * * \\
(0.0000)\end{array}$ & 0.9967 & -3474.67 & -3482.23 & $15.11 * * *$ & 0.082 & 0.103 & -0.137 & 0.349 \\
\hline China & $\begin{array}{l}0.0307 * * * \\
(0.0008)\end{array}$ & $\begin{array}{l}0.5760 * * * \\
(0.0253)\end{array}$ & 0.6067 & -3623.42 & -3624.03 & 1.21 & -0.040 & 0.036 & -0.387 & 0.105 \\
\hline \multicolumn{11}{|c|}{$d_{3}: 512$ observations } \\
\hline & $\alpha$ & $\beta$ & $\alpha+\beta$ & DCC LL & CCC LL & LRT & Mean & S.D. & Min & $\operatorname{Max}$ \\
\hline Canada & $\begin{array}{l}0.0755 * * * \\
(0.0021)\end{array}$ & $\begin{array}{l}0.8406 * * * \\
(0.0075)\end{array}$ & 0.9160 & -1459.49 & -1465.95 & $12.91 * * *$ & 0.694 & 0.084 & 0.366 & 0.858 \\
\hline Brazil & $\begin{array}{l}0.0906 * * * \\
(0.0085)\end{array}$ & $\begin{array}{l}0.8528 * * * \\
(0.0368)\end{array}$ & 0.9434 & -1919.22 & -1926.85 & $15.26 * * *$ & 0.555 & 0.133 & 0.057 & 0.820 \\
\hline the U.K. & $\begin{array}{l}0.0693 * * * \\
(0.0027)\end{array}$ & $\begin{array}{l}0.8288^{* * * *} \\
(0.0224)\end{array}$ & 0.8982 & -1443.92 & -1449.45 & $11.06 * * *$ & 0.634 & 0.083 & 0.243 & 0.828 \\
\hline Germany & $\begin{array}{l}0.1034 * * * \\
(0.0106)\end{array}$ & $\begin{array}{l}0.8053 * * * \\
(0.0834)\end{array}$ & 0.9087 & -1533.36 & -1544.14 & $21.55^{* * *}$ & 0.628 & 0.122 & 0.107 & 0.847 \\
\hline Russia & $\begin{array}{l}0.0461 * * * \\
(0.0011)\end{array}$ & $\begin{array}{l}0.9167 * * * \\
(0.0022)\end{array}$ & 0.9628 & -1987.06 & -1992.88 & $11.64 * * *$ & 0.246 & 0.146 & -0.152 & 0.546 \\
\hline Japan & $\begin{array}{l}0.0678 * * * \\
(0.0014)\end{array}$ & $\begin{array}{l}0.7603 * * * \\
(0.0160)\end{array}$ & 0.8280 & -1669.62 & -1673.48 & $7.71 * *$ & 0.362 & 0.100 & -0.126 & 0.650 \\
\hline Australia & $\begin{array}{l}0.0480 * * * \\
(0.0009)\end{array}$ & $\begin{array}{l}0.9073 * * * \\
(0.0013)\end{array}$ & 0.9553 & -1577.00 & -1581.16 & $8.32 * *$ & 0.456 & 0.101 & 0.075 & 0.694 \\
\hline Hong Kong & $\begin{array}{l}0.0564 * * * \\
(0.0039)\end{array}$ & $\begin{array}{l}0.8092 * * * \\
(0.0092)\end{array}$ & 0.8656 & -1658.96 & -1661.72 & $5.52 *$ & 0.488 & 0.074 & 0.097 & 0.751 \\
\hline India & $\begin{array}{l}0.0305 * * * \\
(0.0002)\end{array}$ & $\begin{array}{l}0.9695 * * * \\
(0.0002)\end{array}$ & 1.0000 & -1778.16 & -1791.41 & $26.51 * * *$ & 0.249 & 0.203 & -0.145 & 0.723 \\
\hline China & $\begin{array}{l}0.0181 * * * \\
(0.0007)\end{array}$ & $\begin{array}{l}0.9142 * * * \\
(0.0150)\end{array}$ & 0.9323 & -1787.36 & -1787.97 & 1.22 & 0.031 & 0.048 & -0.078 & 0.191 \\
\hline \multicolumn{11}{|c|}{$d_{4}: 256$ observations } \\
\hline & $\alpha$ & $\beta$ & $\alpha+\beta$ & DCC LL & CCC LL & LRT & Mean & S.D. & Min & $\operatorname{Max}$ \\
\hline Canada & $\begin{array}{l}0.0061 * * * \\
(0.0003)\end{array}$ & $\begin{array}{l}0.9906 * * * \\
(0.0088)\end{array}$ & 0.9967 & -688.68 & -688.99 & 0.63 & 0.713 & 0.012 & 0.646 & 0.730 \\
\hline Brazil & $\begin{array}{l}0.0437 * * * \\
(0.0006)\end{array}$ & $\begin{array}{l}0.8115 * * * \\
(0.0047)\end{array}$ & 0.8552 & -924.15 & -929.06 & $9.80^{* * *}$ & 0.540 & 0.089 & 0.132 & 0.783 \\
\hline the U.K. & $\begin{array}{l}0.0162 * * * \\
(0.0001)\end{array}$ & $\begin{array}{l}0.9653 * * * \\
(0.0003)\end{array}$ & 0.9815 & -653.94 & -655.96 & 4.03 & 0.717 & 0.041 & 0.616 & 0.803 \\
\hline
\end{tabular}




\begin{tabular}{|c|c|c|c|c|c|c|c|c|c|c|}
\hline Germany & $\begin{array}{l}0.0146^{* * *} \\
(0.0001)\end{array}$ & $\begin{array}{l}0.9756 * * * \\
(0.0001)\end{array}$ & 0.9903 & -707.81 & -709.91 & 4.20 & 0.732 & 0.044 & 0.626 & 0.827 \\
\hline Russia & $\begin{array}{l}0.0205^{* * *} \\
(0.0010)\end{array}$ & $\begin{array}{l}0.9392 * * * \\
(0.0179)\end{array}$ & 0.9598 & -955.16 & -955.86 & 1.40 & 0.425 & 0.053 & 0.292 & 0.532 \\
\hline Japan & $\begin{array}{l}0.0222 * * * \\
(0.0002)\end{array}$ & $\begin{array}{l}0.9592 * * * \\
(0.0002)\end{array}$ & 0.9815 & -794.17 & -798.70 & $9.07 * *$ & 0.369 & 0.129 & -0.023 & 0.699 \\
\hline Australia & $\begin{array}{l}0.0200 * * * \\
(0.0001)\end{array}$ & $\begin{array}{l}0.9574 * * * \\
(0.0007)\end{array}$ & 0.9774 & -747.32 & -750.19 & $5.74 *$ & 0.558 & 0.078 & 0.398 & 0.752 \\
\hline Hong Kong & $\begin{array}{l}0.1288 * * * \\
(0.0056)\end{array}$ & $\begin{array}{l}0.6356 * * * \\
(0.0117)\end{array}$ & 0.7645 & -795.02 & -800.04 & $10.03 * * *$ & 0.465 & 0.141 & -0.307 & 0.802 \\
\hline India & $\begin{array}{l}0.0000 \\
(0.0068)\end{array}$ & $\begin{array}{l}0.0000 \\
(21.7019)\end{array}$ & 0.0000 & -875.94 & -875.94 & 0.00 & 0.277 & 0.000 & 0.277 & 0.277 \\
\hline China & $\begin{array}{l}0.0078 * * * \\
(0.0001)\end{array}$ & $\begin{array}{l}0.9781 \text { *** } \\
(0.0001)\end{array}$ & 0.9859 & -882.14 & -882.33 & 0.39 & -0.026 & 0.034 & -0.074 & 0.066 \\
\hline \multicolumn{11}{|c|}{$d_{5}: 128$ observations } \\
\hline & $\alpha$ & $\beta$ & $\alpha+\beta$ & DCC LL & CCC LL & LRT & Mean & S.D. & Min & $\operatorname{Max}$ \\
\hline Canada & $\begin{array}{l}0.0130 * * * \\
(0.0018)\end{array}$ & $\begin{array}{l}0.0000 \\
(0.9502)\end{array}$ & 0.0130 & -345.23 & -345.25 & 0.04 & 0.686 & 0.008 & 0.646 & 0.709 \\
\hline Brazil & $\begin{array}{l}0.1148 * * * \\
(0.0104)\end{array}$ & $\begin{array}{l}0.6120 * * * \\
(0.0195)\end{array}$ & 0.7268 & -432.35 & -433.87 & 3.05 & 0.602 & 0.086 & 0.208 & 0.792 \\
\hline the U.K. & $\begin{array}{l}0.0969 * * * \\
(0.0080)\end{array}$ & $\begin{array}{l}0.0553 \\
(1.1368)\end{array}$ & 0.1522 & -320.18 & -320.80 & 1.25 & 0.750 & 0.038 & 0.566 & 0.872 \\
\hline Germany & $\begin{array}{l}0.1585^{* * *} \\
(0.0261)\end{array}$ & $\begin{array}{l}0.2959 * * * \\
(0.0324)\end{array}$ & 0.4545 & -365.33 & -366.38 & 2.09 & 0.741 & 0.064 & 0.406 & 0.888 \\
\hline Russia & $\begin{array}{l}0.0000 \\
(0.0000)\end{array}$ & $\begin{array}{l}0.0000 \\
(28.6099)\end{array}$ & 0.0000 & -495.02 & -494.85 & -0.33 & 0.408 & 0.000 & 0.408 & 0.408 \\
\hline Japan & $\begin{array}{l}0.0000 \\
(0.0000)\end{array}$ & $\begin{array}{l}0.0000 \\
(0.8599)\end{array}$ & 0.0000 & -371.66 & -371.66 & 0.00 & 0.608 & 0.000 & 0.608 & 0.608 \\
\hline Australia & $\begin{array}{l}0.0040 \\
(0.0006)\end{array}$ & $\begin{array}{l}0.0000 \\
(2.5409)\end{array}$ & 0.0040 & -357.50 & -357.50 & 0.00 & 0.685 & 0.002 & 0.678 & 0.692 \\
\hline Hong Kong & $\begin{array}{l}0.1486 * * * \\
(0.0183)\end{array}$ & $\begin{array}{l}0.0000 \\
(1.1118)\end{array}$ & 0.1486 & -375.67 & -377.40 & 3.45 & 0.732 & 0.059 & 0.421 & 0.867 \\
\hline India & $\begin{array}{l}0.3113 * * * \\
(0.0152)\end{array}$ & $\begin{array}{l}0.0821 * * * \\
(0.0412)\end{array}$ & 0.3934 & -441.82 & -446.21 & $8.79 * *$ & 0.403 & 0.207 & -0.363 & 0.867 \\
\hline China & $\begin{array}{l}0.1517 * * * \\
(0.0503)\end{array}$ & $\begin{array}{l}0.0615 \\
(0.1088)\end{array}$ & 0.2132 & -443.25 & -443.63 & 0.75 & 0.060 & 0.111 & -0.514 & 0.466 \\
\hline \multicolumn{11}{|c|}{$d_{6}: 64$ observations } \\
\hline & $\alpha$ & $\beta$ & $\alpha+\beta$ & DCC LL & CCC LL & LRT & Mean & S.D. & Min & $\operatorname{Max}$ \\
\hline Canada & $\begin{array}{l}0.0151 * * * \\
(0.0024)\end{array}$ & $\begin{array}{l}0.9332 * * * \\
(0.0098)\end{array}$ & 0.9482 & -173.91 & -174.04 & 0.25 & 0.785 & 0.014 & 0.747 & 0.813 \\
\hline Brazil & $\begin{array}{l}0.0359 * * * \\
(0.0071)\end{array}$ & $\begin{array}{l}0.9092 * * * \\
(0.0186)\end{array}$ & 0.9450 & -238.93 & -238.83 & -0.19 & 0.632 & 0.039 & 0.562 & 0.694 \\
\hline the U.K. & $\begin{array}{l}0.2325^{* * *} \\
(0.0677)\end{array}$ & $\begin{array}{l}0.5676 * * * \\
(0.0509)\end{array}$ & 0.8001 & -147.49 & -150.05 & $5.12 *$ & 0.830 & 0.089 & 0.525 & 0.952 \\
\hline Germany & $\begin{array}{l}0.4871 * * * \\
(0.0230)\end{array}$ & $\begin{array}{l}0.0000 \\
(0.0234)\end{array}$ & 0.4871 & -171.00 & -176.13 & $10.27 * * *$ & 0.746 & 0.152 & 0.009 & 0.967 \\
\hline Russia & $\begin{array}{l}0.0000 \\
(0.0000)\end{array}$ & $\begin{array}{l}0.0000 \\
(0.7478)\end{array}$ & 0.0000 & -260.21 & -259.97 & -0.48 & 0.416 & 0.000 & 0.416 & 0.416 \\
\hline Japan & $\begin{array}{l}0.4618^{* * *} \\
(0.0269)\end{array}$ & $\begin{array}{l}0.0000 \\
(0.0268)\end{array}$ & 0.4618 & -197.64 & -200.06 & $4.84 *$ & 0.606 & 0.210 & -0.270 & 0.953 \\
\hline Australia & 0.0291 & 0.9709 & 1.0000 & -179.82 & -179.87 & 0.09 & 0.720 & 0.027 & 0.643 & 0.770 \\
\hline
\end{tabular}




\begin{tabular}{|c|c|c|c|c|c|c|c|c|c|c|}
\hline & $(0.1023)$ & $(2.5466)$ & & & & & & & & \\
\hline Hong Kong & $\begin{array}{l}0.0662 * * * \\
(0.0032)\end{array}$ & $\begin{array}{l}0.0000 \\
(0.5691)\end{array}$ & 0.0662 & -197.45 & -197.57 & 0.24 & 0.664 & 0.029 & 0.554 & 0.757 \\
\hline China & $\begin{array}{l}0.0000 \\
(0.0587)\end{array}$ & $\begin{array}{l}0.0000 \\
(1144.82)\end{array}$ & 0.0000 & -220.11 & -220.14 & 0.06 & -0.059 & 0.000 & -0.059 & -0.059 \\
\hline
\end{tabular}

Notes: The table summarizes the DCC estimates in bivariate framework with the U.S. for original returns and six time scales. $\alpha$ and $\beta$ are the DCC parameters capturing the effects of the lagged standardized shocks and lagged conditional correlations on current correlations, respectively. The table also presents the log-likelihood values of the DCC and CCC models and the results of the likelihood-ratio test (LRT). The critical values for LRT $\sim \chi_{2}^{2}$ are 4.605, 5.99 and 9.21 for $10 \%, 5 \%$ and $1 \%$ significance levels, denoted with $*$, ** and ***, respectively. A number of descriptive statistics for the dynamic correlations are also presented, including the values for the mean, standard deviation, minimum and maximum. Figures in parentheses denote standard errors. 